Revista de Ensino em Artes, Moda e Design

Dossiê 5

As fontes de pesquisa para moda. Uma aproximação interdisciplinar e arquivista da história da moda: pesquisa e ensino.

DOI: $10.5965 / 25944630332019044$

\title{
REFLEXÕES ACERCA DOS TESTAMENTOS E INVENTÁRIOS PARA O ESTUDO DO VESTUÁRIO NA AMÉRICA PORTUGUESA
}

\author{
Reflections on wills and inventories for the study \\ of clothing in Portuguese America
}

\section{Reflexiones sobre testamentos e inventarios para el estudio de ropa en portuguese america}

Juliana de Mello Moraes ${ }^{1}$ 


\title{
Resumo
}

O propósito deste artigo é refletir acerca das características dos inventários e testamentos, produzidos entre os séculos XVII e XVIII, e suas potencialidades para o estudo das aparências e temas correlatos na América portuguesa. Além disso, se discute a possibilidade dessa documentação para a análise das conexões materiais, em especial presentes no vestuário, entre os diversos territórios pertencentes à Coroa portuguesa. Avaliar essas vinculações permite acessar as especificidades das diferentes localidades da América portuguesa, tendo em vista suas conexões intercontinentais. Entretanto, constata-se que apesar das inúmeras possibilidades de trabalho com essas fontes, ainda são escassos os estudos sobre as dinâmicas entre aquisição do vestuário, as aparências e as configurações sociais e suas conexões no império português.

Palavras-Chave: Inventários e testamentos. Moda. América portuguesa

\begin{abstract}
The purpose of this article is to reflect on the characteristics of inventories and wills, produced between the seventeenth and eighteenth centuries, and their potential for the study of appearances and related themes in Portuguese America. Furthermore, it is discussed the possibility of using this documentation for the analysis of material connections, especially present in clothing, between the various territories belonging to the Portuguese Crown. Evaluating these links allows us to access the specificities of the different localities of Portuguese America, considering their intercontinental connections. However, it appears that despite the numerous possibilities of working with these sources, there is still little work on the dynamics between clothing acquisition, appearances and social configurations and their connections in the Portuguese empire.
\end{abstract}

Keywords: Inventories and wills. Fashion. Portuguese America.

\begin{abstract}
Resumen
El propósito de este artículo es reflexionar sobre las características de los inventarios y testamentos, producidos entre los siglos XVII y XVIII, y su potencial para el estudio de las apariencias y temas relacionados en la América portuguesa. Además, se discute la posibilidad de esta documentación para el análisis de las conexiones materiales, especialmente presentes en la ropa, entre los diversos territorios que pertenecen a la Corona portuguesa. Evaluar estos enlaces nos permite acceder a las especificidades de las diferentes localidades de la América portuguesa, considerando sus conexiones intercontinentales. Sin embargo, parece que a pesar de las numerosas posibilidades de trabajar con estas fuentes, los estudios sobre la dinámica entre la adquisición de ropa, las apariencias y las configuraciones sociales y sus conexiones en el imperio portugués aún son escasos.
\end{abstract}

Palabras Clave: Inventarios y testamentos. Moda. América portuguesa. 


\section{INTRODUÇÃO}

A produção historiográfica sobre a moda avançou consideravelmente nas últimas décadas, em decorrência, principalmente, do crescimento do número de pós-graduações no Brasil (BONADIO, 2010, p. 76; RAINHO, 2015, p. 2). Entretanto, essa expansão não se limita somente ao desenvolvimento das instituições acadêmicas, estando também relacionada às mutações no próprio fazer historiográfico. Nesse sentido, o estabelecimento da moda enquanto objeto de pesquisa se insere num movimento mais amplo de transformação da própria área da História.

A introdução de novos objetos, abordagens e problemas, como enfatizou a coleção organizada por Jaques Le Goff e Pierre Nora, publicada originalmente em 1974, evidenciava o alargamento das possibilidades de investigação entre os historiadores. Emergiu a preocupação com sujeitos (jovens e crianças), ocasiões (festas, procissões, por exemplo), mentalidades e matérias (cozinha, livro, língua etc.), antes, muitas vezes, ignorados na área.

Dentre os novos objetos de investigação relacionados à cultura material encontram-se aqueles presentes no cotidiano das populações, como a alimentação, os utensílios e objetos do universo doméstico, incluindo o vestuário.

$O$ estudo de Fernand Braudel sobre as estruturas e a vida material no Mediterrâneo, entre os séculos XV e XVIII, por exemplo, enfatiza que "a história das roupas é menos anedótica do que parece" (BRAUDEL, 1995, p. 281). Tal afirmação se baseia na percepção da complexidade que cerca o vestuário, uma vez que permite ao pesquisador elaborar problemáticas distintas a respeito das matérias primas, dos modos e custos de produção e das relações comerciais, bem como "da fixidez cultural, das modas e das hierarquias sociais" (BRAUDEL, 1995, p. 281).

Logo, atentar para a complexidade inerente à cultura material é fundamental, pois, como indica Daniel Roche, "os objetos, as relações físicas ou humanas que eles criam não podem se reduzir a uma simples materialidade, nem a um simples instrumentos de comunicação ou de distinção social" (ROCHE, 2000, p. 13).

No entanto, a ampliação dos objetos de estudo da História significou, paralelamente, o alargamento do conceito de fonte, uma vez que essa expansão suscitou mudanças na epistemologia da própria produção historiográfica. Enquanto os historiadores do século XIX realçaram a importância do documento escrito para a análise histórica, ao longo do século XX, essa noção ampliou-se. Inclusive, o reconhecimento de materiais arqueológicos, iconográficos e orais como fontes foi acompanhado da introdução e validade de outras produções textuais para a pesquisa. Nesse sentido, um documento antes considerado "fantasioso, mítico ou pouco preocupado com a visão empírica do mundo" (KARNAL, TATSCH, 2015, p. 16) tornou-se válido para a análise historiográfica.

A introdução de novos temas e a mudança no conceito de fonte favoreceram a multiplicação das categorias documentais. Assim, para o estudo do vestuário, por exemplo, pode-se recorrer às roupas, aos tecidos, às imagens e à outras fontes características da história familiar, social, econômica, entre outras (ROCHE, 2007, p. 23).

No rol de fontes pertinentes para a análise do vestuário e das aparências nas sociedades ocidentais para o período denominado tradicionalmente de Idade Moderna, destacam-se os inventários e, em menor medida, os testamentos. Com inquestionável valor para a análise dos guarda-roupas de populações e períodos carentes de outras 
fontes tanto iconográficas quanto materiais, os inventários e testamentos permitem acessar informações valiosas a respeito das roupas e outros acessórios do passado.

Por isso, o propósito deste artigo é refletir acerca das características dos inventários e testamentos, produzidos entre os séculos XVII e XVIII, e suas potencialidades para o estudo das aparências e temas correlatos na América portuguesa. Além disso, se discute as possibilidades dos inventários e testamentos para sinalizarem as conexões materiais, em especial do vestuário, entre os diversos territórios do império português. Avaliar essas vinculações permite acessar as especificidades das sociedades da América tendo em vista suas conexões intercontinentais.

Se a materialidade em si congrega a complexidade inerente às relações humanas, entende-se o vestuário como um fato social de comunicação, o qual expressa também a cultura, as sensibilidades, as técnicas de produção e o consumo (ROCHE, 2000 , p. 13). Enquanto as aparências aqui são compreendidas "enquanto construtora de sociabilidades" (SANT'ANNA, 2016, p. 11), ou seja, pautavam as relações entre os distintos sujeitos históricos.

\title{
2 OS INVENTÁRIOS E TESTAMENTOS PARA O ESTUDO DO VESTUÁRIO
}

Tanto os inventários quanto os testamentos são fontes referentes ao momento da morte de um indivíduo, porém constituem-se num farto manancial de informações sobre a sua vida. Aspectos materiais e espirituais se revelam a partir dos dados fornecidos por essa documentação. No século XVIII, o inventário era definido como o "registro ou papel em que estão registrados os moveis, os papeis e varias cousas que há em huma casa" (BLUTEAU, 1728, p. 182). Desse modo, consistia num rol dos bens móveis, imóveis e semoventes pertencentes ao falecido (a). Enquanto o testamento indicava as vontades do seu autor e apesar de proporcionar ao testador a hipótese de dispor dos seus bens, na América portuguesa revela principalmente as preocupações com a salvação da alma.

Por isso, mesmo tendo como denominador comum a morte, essas fontes - inventários e testamentos - divergem quanto aos seus conteúdos e intencionalidades.

O testamento manifesta os desígnios do seu autor, interferindo sobre a partilha de bens após a sua morte. No entanto, para ser válido deveria atender alguns requisitos legais, de acordo com a legislação vigente nos séculos XVII e XVIII:

\begin{abstract}
o testamento devia ser escrito por ou na presença de um tabelião, acompanhado de mais cinco testemunhas, livres, varões e maiores de 14 anos de idade. Todos, além do testador, tinham que assinar o documento. Porém, não sabendo o testador escrever, assinava por ele uma das testemunhas e ao lado dessa assinatura ele colocava o seu sinal, sendo o mais comum a cruz (FURTADO, 2015, p. 95).
\end{abstract}

Em certas ocasiões, algumas dessas exigências poderiam ser suprimidas, porém a necessidade de testemunhas e o registro pelo tabelião mantinham-se, exceto para os soldados mortos em batalha. Esses poderiam testar oralmente ou por escrito diante de somente duas testemunhas.

As apreensões com a salvação da alma ocupavam sobremaneira os testadores, uma vez que dispunham principalmente sobre os ritos fúnebres, a mortalha e outros atos destinados a auxiliar a alma.

Diferentemente do testamento, o inventário ocorria após o falecimento do indivíduo e tinha como finalidade arrolar os bens materiais para posterior divisão entre os herdeiros. Nele registrava-se o tipo, as características e o valor monetário dos bens, bem 
como as dívidas ativas e os débitos do defunto. O inventário consistia num dos elementos da partilha do patrimônio, sendo regulado pela legislação. Não obstante, a confecção do inventário judicial durante o período aqui abordado ocorria somente em casos excepcionais, pois os herdeiros poderiam realizar a partilha de modo privado quando amigavelmente acordado. Esses, entretanto, como documentos privados, além de serem difíceis de localizar, em muitos casos não foram preservados, inviabilizando a pesquisa histórica.

De acordo com a legislação da época, a obrigatoriedade da confecção de inventário judicial acontecia quando o falecido tinha herdeiros com menos de 25 anos, quando não tinha herdeiro, quando solteiro e sem herdeiros presumidos ou nos casos em que indivíduo morria distante da sua residência. Por isso, muitos falecidos mesmo possuindo bens não geravam inventários judiciais.

Além dessas questões, outra distinção importante entre inventários e testamentos consiste na intencionalidade da fonte. Como era elaborado durante a vida do indivíduo, o testamento expressava as vontades e intenções do testador ou testadora em relação a seus bens, aos ritos fúnebres, entre outros. Para as questões religiosas o testador poderia despender até um terço do seu patrimônio, sendo conhecida essa quantia como a "terça". Nesse sentido, os desígnios do testador quanto ao destino de seus bens e, em especial, dos cuidados para sua alma são relevantes para o estudo das práticas religiosas, das crenças, devoções etc.

Porém, se o testamento é uma fonte voluntária, o inventário é o inverso. Elaborado após a morte, o inventário para a partilha de bens ocorria independentemente do seu protagonista, por isso é considerado uma fonte involuntária. Contudo, testamentos e inventários se relacionam e se complementam, inclusive havia a necessidade de respeitar e transcrever o testamento no início dos autos de inventariação dos bens, como determina o Livro do Provimento dos Órfãos, o qual vigorou entre 1729 e 1855 . Nesse livro consta a forma como deveriam ser elaborados os inventários, determinando que:

1) O termo de abertura, em que, entre outros dados, informa-se o local, a data, o juiz responsável e a data do óbito;

2) A transcrição do testamento, quando há,

3) A designação de tutor, quando há herdeiros menores e o cônjuge sobrevivente é mulher, sendo obrigatória quando o espólio é de valor elevado;

4) A inventariação e avaliação dos bens por avaliador designado (bens móveis, destacando-se prata e ouro; bens imóveis; bens semoventes, animais e escravos; dívidas ativas e passivas);

5) Partilha dos bens entre os herdeiros;

6) Codicilo, quando houver (FURTADO, 2015, p.105).

As disposições legais indicavam o formato do documento, no entanto outros importantes elementos dos inventários dependiam essencialmente de fatores sociais e econômicos do contexto. Esse é o caso do rol composto pelos avaliadores. Responsáveis por apontar os bens e seus respectivos valores, eles deveriam ser juramentados pela câmara municipal da cidade ou vila (FLEXOR, 2005, p. 4) e suas anotações definiam as características e respectivo valor de cada objeto do falecido, resultando na quantia total do espólio. Além disso, os itens arrolados nos inventários possuíam descrição, por vezes, pormenorizada com indicações sobre o estado de conservação e uso. Essas informações resultam num importante recurso para estudar os patrimônios, a cultura material, o consumo e outros aspectos do cotidiano das populações do período.

Como mencionado, os inventários eram elaborados após a morte do indivíduo e se referem a um momento específico na vida das pessoas mais afortunadas. Por isso, 
é preciso considerar a idade e o estado sacramental do inventariado(a), uma vez que os bens, incluindo o vestuário, variavam para além das condições financeiras, transformando-se de acordo com o gênero e a condição matrimonial (casada, solteira ou viúva) (SILVA, 2018, p. 145).

Todavia, como não abarcam a totalidade dos proprietários, uma vez que, nos séculos XVII e XVIII, sua elaboração só ocorria em casos de litígio, os inventários possuem uma representatividade social controversa, pois se referem a uma parcela específica da população (ROCHE, 2007, p. 82).

Outra importante característica dessas fontes consiste na possível arbitrariedade dos apontamentos ou do ocultamento de bens motivados por diversas razões. Nesse sentido, toda a pesquisa com base em inventários deve considerar que existem, por vezes, lapsos decorrentes de doações ou ocultação de patrimônio pelos herdeiros, casos relativamente comuns em relação ao vestuário (ROCHE, 2007, p. 98).

Apesar das possíveis imprecisões na descrição dos bens e seus valores, os inventários possuem informações inquestionavelmente relevantes para o estudo da cultura material do passado. Todavia, o seu uso na investigação demanda alguns cuidados, porque, tal como outros documentos, apresentam diversas lacunas.

Porém, a despeito das lacunas e das especificidades, esses documentos são fundamentais para o estudo do vestuário e das aparências, especialmente na América portuguesa entre os séculos XVII e XVIII, pois são raras ou inexistentes outras fontes (por exemplo, imagens ou têxteis) que especifiquem detalhadamente as roupas e adornos. Além disso, os inventários, mesmo possuindo uma representatividade circunscrita, permitem ainda relacionar os guarda-roupas aos distintos grupos sociais do período.

\section{AS ESPECIFICIDADES NOS TESTAMENTOS E INVENTÁRIOS DA AMÉ- RICA PORTUGUESA}

Desde o início do século XX, se verifica a existência de pesquisas que utilizam os inventários para investigar a cultura material do passado.

Em seu trabalho sobre a vida cotidiana dos paulistas, por exemplo, Alcântara Machado enfatizou a necessidade de estudar as pessoas comuns, os indivíduos anônimos e os aspectos mais triviais da sua existência (MACHADO, 1980, p. 29). No intuito de se opor à historiografia dedicada aos ilustres, o autor utilizou os inventários e testamentos elaborados entre os séculos XVI e XVII, para sua compor seu trabalho. Publicado em 1929 , esse estudo pioneiro tanto no tema quanto no uso das fontes, revela uma sociedade carente de recursos materiais, na qual os utensílios, as moradias e as roupas eram modestos ou escassos. Quanto ao vestuário, o autor sublinha a precariedade do vestir, destacando, todavia, alguma variedade nas peças masculinas e femininas. Os vestidos de gala e as joias compunham os guarda-roupas das mulheres, revelando a preocupação com o consumo de peças indicadoras de status e prestígio. Como esclarece Vainfas, Alcântara Machado "explorou ao máximo os Inventários e Testamentos mandados pu ılicar por Washington Luís, em 1920, e traçou panorama vasto sobre a vida humilde dos bandeirantes" (VAINFAS, 2009, p. 222).

Entretanto, a valorização dos estudos sobre distintos aspectos do cotidiano, incluindo o vestuário das populações de outros tempos, emergiu na historiografia brasileira, sobretudo, a partir da década de 1990 (SCHWARTZ, 2009, p. 182), impulsiona- 
da, principalmente, pelas mudanças alavancadas pela nova história francesa (PRIORE, 1997, p. 261-262). Como referido, esse movimento promoveu a visibilidade a sujeitos e objetos antes marginais na historiografia, bem como ratificou o uso dos inventários para o estudo da cultura material de outros tempos.

Dentre os elementos da cultura material, destaca-se a aquisição do vestuário, a qual relacionava-se intimamente com as redes de inter-relações e interdependências dos indivíduos, pois a preocupação com a aparência ocorria em função da necessidade de preservar ou ampliar o status social. Isso fomentava entre as famílias, principalmente das elites, a aquisição de vestuário considerado adequado.

Porém, a análise dos guarda-roupas de um determinado contexto exige o uso de um conjunto vasto de fontes. A historiografia, inclusive, enfatiza a necessidade de contemplar de modo serial inventários e testamentos, uma vez que raramente é possível responder a qualquer problemática a partir de uma dessas fontes isoladamente. Ao mesmo tempo, é fundamental verificar a relação entre a quantidade de inventários disponíveis e a totalidade da população estudada, no intuito de estabelecer a representatividade das fontes. Por isso, a compreensão diacrônica do vestuário e sua relação com os distintos grupos sociais numa determinada localidade exige a análise de um conjunto alargado de inventários.

Como informa sobre o patrimônio, os créditos e as dívidas do defunto, os inventários também revelam dados sobre a circulação dos objetos, incluindo das roupas e outros ornamentos (SILVA, 2015, p. 198). Consequentemente, o estudo dos guarda-roupas encontra, por vezes, nessa documentação dados para aferir as reciprocidades familiares, as transações comerciais, os grupos nelas envolvidos e a abrangência geográfica do comércio. Porém, se os inventários esclarecem sobre a circulação, também podem ocultar outros fenômenos característicos da época, incluindo a revenda, o empréstimo e a reutilização das roupas (ROCHE, 2007, p. 85).

Embora apresente algumas dificuldades, as informações constantes nessa documentação permitem ainda verificar as conexões entre diferentes espaços. Como arrolam o vestuário de homens e mulheres, mencionando as características de cada peça de roupa, é possível observar os atributos e a origem dos materiais, em especial dos têxteis. Para determinar o valor das roupas, os avaliadores apontavam também seu estado de conservação, ou seja, se estava nova, usada, muito usada ou, até mesmo, estragada. Essa característica possibilita avaliar o tempo de uso das peças, as possíveis preferências ou necessidades de roupa do inventariado.

A origem das matérias-primas utilizadas para a confecção de roupas, segundo Daniel Roche, era normalmente local (ROCHE, 2000, p. 264). No entanto, essa premissa minimiza o movimento e as trocas proporcionadas pelas navegações. Se a Europa se apresentava como entreposto comercial do globo, mantendo sua produção e consumo majoritariamente regionais, com poucas exceções, "the flow of new goods has generally been into, not out of, Latin America" (BAUER, 2001, p. 8).

Nesse sentido, a circulação de mercadorias no império português ocorria entre distintos continentes, consequentemente eram inúmeros os produtos transportados pelas embarcações. Todavia, dentre as mercadorias oriundas da Europa chegavam à América, principalmente, o azeite, a farinha, o bacalhau, os vinhos, as ferramentas e objetos de ferro, os tecidos de lã e peças como perucas e meias de seda (RUSSELL-WOOD, 2016, p. 182). 
O desenvolvimento dos circuitos comerciais incluiu também os contatos entre África e América sem a ligação com Portugal continental, emergindo um comércio português entre continentes sem a vinculação ao centro imperial. Inclusive, a articulação nos territórios da Coroa portuguesa demonstra que o

\begin{abstract}
Atlântico desempenhou o papel de estabelecer os ritmos do império, influenciava a governança, as comunicações, o comércio, a migração, os intercâmbios culturais, os movimentos de flora e fauna e até mesmo como os indivíduos se auto identificavam. Rotas conectavam todos os pontos no Atlântico português e facilitavam o intercâmbio entre a África e a América portuguesas. Os arquipélagos portugueses eram pontos de articulação entre o norte e o sul e entre o leste e o oeste (RUSSELL-WOOD, 2009, p.23).
\end{abstract}

A extensão e dimensão dessas relações comerciais podem ser avaliadas por meio dos inventários como já indica a historiografia, sendo recorrente a presença na América de têxteis, roupas e adornos das mais variadas procedências, incluindo África, Macau, Índia, Holanda, Bretanha, entre outros (RUSSELL-WOOD, 2016, p. 190; PEREIRA, 2011, p. 339).

Porém, se explicitam as conexões entre territórios longínquos, os testamentos e inventários também sinalizam as especificidades e ritmos locais no que se refere aos materiais empregados na sua confecção, na aquisição e uso do vestuário e outros adornos. Paralelamente, o estudo sincrônico dessa documentação propicia a análise das aparências e o seu papel entre os indivíduos em configurações sociais específicas

\title{
4 CONCLUSÃO
}

Os inventários e testamentos são documentos primordiais para acessar os espólios individuais, pois elaborados no contexto da morte, arrolavam os bens móveis e imóveis para transmissão e partilha entre os herdeiros. As potencialidades dessas fontes permitem aos historiadores avaliarem diversos aspectos do cotidiano e da cultura material de determinado contexto. Embora possua fragilidades, essa documentação é especialmente relevante para o estudo do vestuário e das aparências desde que sejam consideradas as suas especificidades.

Entretanto, apesar de alguns estudos se dedicarem a análise do vestuário e das aparências, permanece ainda precário o conhecimento a respeito das dinâmicas entre aquisição do vestuário, as aparências e as configurações sociais nos diferentes contextos da América portuguesa.

No entanto, as limitações impostas pelas lacunas existentes no registro dos patrimônios não superam as vantagens, especialmente para algumas temáticas, pois "estudos sobre indumentárias podem e devem se valer desses documentos, principalmente os mais antigos, que trazem listados todo tipo de vestimentas, fornecendo pistas sobre cores, tecidos, materiais, adornos, joias, sapatos, fivelas, perucas, etc., permitindo inclusive perceber os efeitos a cada extrato social" (FURTADO, 2015, p. 113).

A escassez de pesquisas sobre o vestuário e as aparências na América portuguesa na área de História contrasta com a ampliação no número de teses e dissertações dedicadas ao tema da moda e afins no país nas últimas décadas. (BONADIO, 2010, p. 73-74; RAINHO, 2015, p. 3-10). Todavia, embora sejam exíguas, as teses e dissertações sobre as temáticas em questão são notáveis pela qualidade e pela variedade de documentação utilizada (MORAES, 2018, p. 7-14). Paralelamente, a partir desses estudos 
se confirma a relevância dos testamentos e inventários post-mortem para a análise do vestuário e das aparências para o período. Entretanto, isso não excluí o valor de outros documentos produzidos por instituições político-administrativas, como as câmaras municipais, a legislação portuguesa, a iconografia, os relatos de viajantes e outras narrativas e discursos de autoridades para análise do tema.

\section{REFERÊNCIAS}

BAUER, Arnold. J. Goods, Power, History. Latin America's material culture. Cambridge: Cambridge University Press, 2001.

BONADIO, Maria Claudia. A produção acadêmica sobre moda na pós-graduação no Brasil. lara - Revista de Moda, Cultura e Arte, v.3, n.3, 2010. Disponível em: <http://www1. sp.senac.br/hotsites/blogs/revistaiara/wpcontent/uploads/2015/01/03_IARA_vol3_n3_ Dossie.pdf>. Acesso em 12 de fev. 2018.

BRAUDEL, Fernand. Civilização material, economia e capitalismo, séculos XV-XVIII. As estruturas do cotidiano. vol. 1. São Paulo: Martins Fontes, 1995.

FLEXOR, Maria Helena O. Inventários e testamentos como fontes de pesquisa. Histedbr, 2005. Disponível em: <http://www.histedbr.fae.unicamp.br/navegando/artigos_frames/artigo_074.html> Acesso 23 jun. 2018.

FURTADO, Júnia Ferreira. Testamento e inventários. A morte como testemunho da vida. In: PINSKY, Carla B.; LUCA, Tania Regina de (orgs.). O historiador e suas fontes. São Paulo: Editora Contexto, 2015.

KARNAL, L. TATSCH, Flavia G. Documento e História. A memória evanescente. In: PINSKY, Carla B.; LUCA, Tania Regina de (orgs.). O historiador e suas fontes. São Paulo: Editora Contexto, 2015.

MACHADO, Alcântara. Vida e morte do bandeirante. São Paulo: Edusp, 1980.

MORAES, Juliana de Mello. "Prodigiosa mudança das vestiduras": a historiografia sobre a moda na América portuguesa. In: Anais do $14^{\circ}$ Colóquio de Moda, Curitiba, ABEPEM, 2018. Disponível em: <http://www.coloquiomoda.com.br/anais/Coloquio\%20 de $\% 20$ Moda $\% 20-\% 202018 /$ Grupos $\% 20$ de $\% 20$ Trabalho/GT\%2004\%20-\%20Moda,\%20 Cultura\%20e\%20Historicidade/Juliana\%20de\%20Mello\%20Moraes\%20-\%20PRODIGIOSA\%20MUDAN\%C3\%87A\%20DE\%20VESTIDURAS\%20-\%20A\%20HISTORIOGRAFIA\%20SOBRE\%20A\%20MODA\%20NA\%20AM\%C3\%89RICA\%20PORTUGUESA.pdf> Acesso em 11 jun. de 2019.

PEREIRA, Ana L. C. "Lençóis de linho, pratos da Índia e brincos de filigrana": vida cotidiana numa vila mineira setecentista. Estudos Históricos. v. 24, n. 48, p. 331350, 2011. Disponível em: <http://www.scielo.br/scielo.php?script=sci_arttext\&pi$\mathrm{d}=\mathrm{S} 0103-21862011000200005 \&$ Ing=en\&nrm=iso $>$. Acesso 10 mai. 2019.

PRIORE, Mary Del. História do cotidiano e da vida privada. In: CARDOSO, Ciro Flamarion; VAINFAS, Ronaldo (orgs.). Domínios da História: ensaios de teoria e metodologia. Rio de Janeiro: Campus, 1997.

RAINHO, Maria do Carmo. A moda como campo de estudos do historiador: balanço da produção acadêmica no Brasil. Anais do $11^{\circ}$ Colóquio de Moda, Curitiba, ABEPEM, 2015. Disponível em: <http://www.coloquiomoda.com.br/anais/Coloquio\%20de\%20 Moda\%20-\%202015/ARTIGOS-DE-GT/GT06-MODA-E-CULTURA/GT-6-A-MODA-COMO-CAMPO-DE-ESTUDOS-DO-HISTORIADOR.pdf> Acesso em: 10 de jun. 2018. 
ROCHE, Daniel. História das coisas banais. Nascimento do consumo séc. XVII e XVIII. Rio de Janeiro: Rocco, 2000.

ROCHE, Daniel. A Cultura das Aparências: Uma história da Indumentária (séculos XVII-XVIII). São Paulo: Editora Senac, 2007.

RUSSELL-WOOD, A. J. R. O império português. 1415-1808. O mundo em movimento. Lisboa: Clube do Autor, 2016.

RUSSELL-WOOD, A. J. R. Sulcando os mares: um historiador do império português enfrenta a "Atlantic History". História, v. 28, n. 1, p. 17-70, 2009. Disponível em <http://www. scielo.br/scielo.php?script=sci_arttext\&pid=S0101-90742009000100002\&lng=pt\&nrm=iso>. acessos em 05 jul. 2016.

SANT'ANNA, Mara Rúbia. O Brasil por suas aparências. Sociabilidades coloniais entre o ver e o ser visto. São Paulo: Estação das Letras e Cores, 2016.

SCHWARTZ, Stuart. A historiografia dos primeiros tempos do Brasil moderno. Tendências e desafios das duas últimas décadas. História: questões \& debates, n. 50, 2009, p. $175-216$.

SILVA, Camila Borges da. Os inventários no estudo da indumentária: possibilidades e problemas. Acervo, Rio de Janeiro, v. 31, n. 2, p. 142-160, maio/ago. 2018.

SILVA, Luciana da. A circulação de artefatos por meio das disposições testamentárias: apontamentos sobre as vestimentas na vila de São Paulo (1580-1640). Anais do Museu Paulista. São Paulo. N. Sér. v.23. n.1. p. 195-220. jan.- jun. 2015. Disponível em: <http:// www.redalyc.org/articulo.oa?id=27342180008>

VAINFAS, Ronaldo. História cultural e historiografia brasileira. História: Questões \& Debates, Curitiba, n. 50, p. 217-235, 2009.

DOI: http://dx.doi.org/10.5965/25944630332019044 